\title{
Synthesis of bis(indolyl)methanes using molten $N$-butylpyridinium bromide
}

\author{
Gaurav Gupta a, Ganesh Chaudhari b, Preeti Tomar c, Yogesh Gaikwad d, Rameez Azad d, \\ Girish Pandya d, Govinda Waghulde e and Kesharsingh Patil a,*
}

a School of Chemical Sciences, North Maharashtra University, Jalgaon, 425001, India

b Department of Chemistry, Moolji Jaitha College, Jalgaon, 425001, India

c Department of Applied Chemistry, Jaywant Shikshan Prasarak Mandal's Rajashi Shahu College of Engineering, Pune, 411027, India

d Anacon Laboratories, Nagpur, 440010, India

e Department of Chemistry, Dadasaheb Devidas Namdeo Bhole, College, Bhusawal, 425201, India

${ }^{*}$ Corresponding author at: School of Chemical Sciences, North Maharashtra University, Jalgaon, 425001, India.

Tel.: +91.0257.2272629; Fax: +91.0257.2258403. E-mail address: patilkesharsingh@hotmail.com (K. Patil).

\section{ARTICLE INFORMATION}

Received: 16 November 2012

Received in revised form: 26 November 2012

Accepted: 29 November 2012

Online: 31 December 2012

\section{KEYWORDS}

\section{Molten salt}

Designer solvent

Aromatic aldehydes

Bis(indolyl)methanes

Condensation reaction

Electrophilic substitution reaction

\section{Introduction}

During the past decade more and more researchers and technologists in increasingly diverse areas have become interested in ionic liquids. Hence, this field continues to develop at an incredible rate. Some simple physical properties like low melting temperature, negligible vapor pressure, nonflammability, thermal conductivity, high thermal stability etc. of the ionic liquids make them a promising green alternatives for volatile organic compounds. Moreover, their physicochemical properties can be finely tuned by the appropriate selection of the cation and/or anion. This tuning ability of ionic liquids enables them as a "Designer Solvents" for organic conversions. To date, the large application window of ionic liquids in electrochemistry, solar device, separation science, heat transfer fluid, catalysis and in polymer science, strongly boost their glamour in every domain of the present day science [1-4]. It can be viewed that the difference between ionic liquids and molten salts is just a matter of degree literally [5]. In accordance to this classification, we treated $\mathrm{N}$-butyl-pyridinium bromide ([Bpy] $[\mathrm{Br}]$ ) onward as a molten salt.

It is well known that, the exceptionally large number of alkaloids and medicinally important compounds are derived from indole. Its reactions, and particularly the synthesis of complex derivatives, occupy central stage in heterocyclic chemistry. As comparable to other indole derivatives, family of bis(indolyl)methanes (BIMs) are well known for their biological activity. BIMs are potential chemo-preventive, and have been phyto-chemically derived from Brassica vegetables [6]. BIMs are the naturally occurring compounds and are produced during the autolytic breakdown of glucobrassicin, and that occurs exclusively in the crucifereae [7]. BIMs are effective towards estrogen-regulated events in human breast cancer cells, and are found as a promoter-specific activator of estrogen receptor even in the absence of $17 \beta$-estradiol [8]. In addition to that, these compounds exhibits a broad spectrum of anticancer activities by inducing cancer cell differentiation, growth inhibition, and apoptosis [9], as well as analgesic and antiinflammatory activities [10] are also reported.

In recent years, the synthesis of BIMs has been reported using a wide-ranging group of catalysts. Many of the methods were designed to use promoters, which include acids [11-14], surfactants [15], ammonium salts [16,17], trichloro-1,3,5triazine [18], transition metal complexes [19-25], zeolites [2629], molecular iodine $[30,31]$, montmorillonite K-10 clay [3234], under microwave irradiation [35]. In addition to this neoteric materials (ionic liquids) [36,37], protic solvent [38], and deep eutectic solvent systems [39] have also been used for the synthesis of BIMs. Most of the formerly reported methods experienced the numerous setbacks, which often include requirement of a stoichiometric amount of the Lewis acid, prolonged reaction time, expensive and toxic catalysts, and solvents. However, still there is a need of more competent, cost effective and environmentally friendly route for the synthesis of such valuable indole derivatives.

Osteryoung et al. [40] pioneered the first room temperature pure electrolyte of pyridine family in 1975. Thereafter very few research articles [41-47] which deal with the physical properties of pyridinium based ionic liquids were cited. Herein, we report an efficient molten salt [bpy][Br] mediated synthesis of BIMs, and discuss the plausible mechanism of the synthesis. 


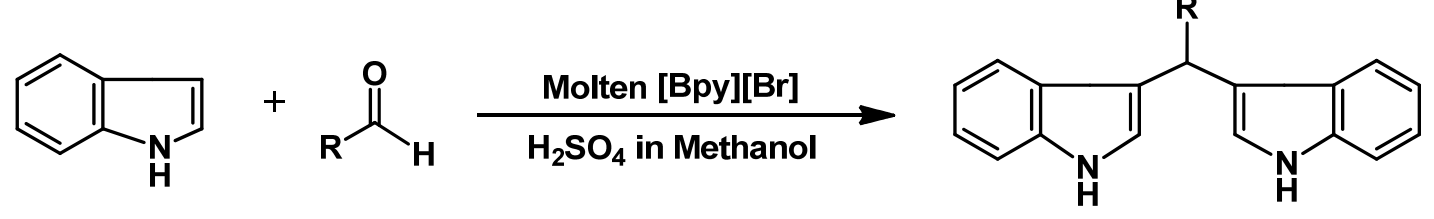

Scheme 1

\section{Experimental}

All commercially available reagents were used without further purification. Melting points were determined in open capillary and are uncorrected. TGA analysis was done using Shimadzu TGA-50 instrument. FT-IR spectral analysis was carried out using IR-Affinity model (Shimadzu), chemical shifts of ${ }^{1} \mathrm{H}$ and ${ }^{13} \mathrm{C}$ (300 and $75 \mathrm{MHz}$, respectively) spectra's were recorded using Bruker instrument. Mass spectra's were recorded using ESI-MS/MS set ups having triple quadruple detection system by Thermo-Fischer.

\subsection{Synthesis and characterization of [Bpy][Br]}

In our earlier communication [48], we suggested an effective, inexpensive and a rapid method for the synthesis of imidazolium and pyridinium based ionic liquids and molten salt respectively. In order to set an excellent strategy for the synthesis of BIMs, the molten [Bpy][Br] used synthesized, purified and then dried under reduced pressure.

Shimadzu UV-Visible spectrophotometer with UV-Probe 3.5 software was used for analysis of $[\mathrm{Bpy}][\mathrm{Br}]$. For the authenticity of the results the instrument was calibrated using $0.1 \mathrm{M} \mathrm{KNO}_{3}$ (which shows absorption at $302 \mathrm{~nm}$ ), and other UV absorbing standards such as benzene, ethanol etc.

Before, the implementation of the adopted methodology i.e. molten salt mediated synthesis of BIMs, it is essential to have the knowledge of exact amount of water present in the molten salt. Systronics Auto KF-Titrator 349 an automatic apparatus was used to carry out Karl Fischer titrations for accurate determinations of moisture. Pyridine-free 526 Karl-Fischer Reagent (single solution) of Fisher Scientific (Qualligens) was used for analysis. The Karl-Fischer reagent was standardized against sodium tartaratedihydrate and immediately used to find moisture content in [Bpy][Br]. We could able to determine the moisture content up to the level of 5 to $10 \mathrm{ppm}$.

Thermal stability of the molten salt was checked by performing TGA analysis. During the analysis the sample was heated in aluminium pans under nitrogen atmosphere by maintaining heating rate $10{ }^{\circ} \mathrm{C} / \mathrm{min}$. The analysis by FT-IR, ${ }^{1} \mathrm{H}$ NMR and Mass spectral response showed good agreement with similar data reported in literature [49].

\subsection{Representative experimental procedure for the synthesis of BIMs}

In a melt of [Bpy][Br] (1 mmol) addition of indole $(2 \mathrm{mmol})$ and appropriate aldehyde $(1 \mathrm{mmol})$ was made. Then the mixture was hold to cool down, during cooling it was converted into a sticky froth. The resulting froth was treated with acidified methanol (Caution: careful handling is required when dealing with sulphuric acid in methanol, because it is an explosive mixture) to form a homogeneous mixture. Finally, the solution was poured into ice-cooled water to yield crystals of bis(indolyl)methanes (Scheme 1).

During the course of the reaction TLC was taken after time interval of five minutes and exactly after 15 minutes spots of starting material was found to disappear (taking into consideration the complete consumption of indole). The suitability of an acidified methanol system was checked, by dividing the froth into five portions, these portions were treated with different solvents like water, methanol, ethanol, acetic acid and sulphuric acid. Finally the acidified methanol system found to afford the expected yield. Thereafter the entire product was dissolved in dichloromethane. The solution was washed several times with water. Finally the shiny crystals of the products were yielded with subsequent removal of the solvent dichloromethane on rotary evaporator.

After purification, the compounds were identified and confirmed by comparing their Physical constants, mass, ${ }^{1} \mathrm{H}$ and ${ }^{13} \mathrm{C}$ NMR, FT-IR spectral data, with the data available in literature $[12,38,39]$.

2,2'-(Phenylmethylene)bis(indole) [1a]: Yield: 92\%. M.p.: 122-126 ${ }^{\circ} \mathrm{C}$. FT-IR (KBr, $\left.v, \mathrm{~cm}^{-1}\right): 3410,2960,1610,1456,800$, 744. ${ }^{1} \mathrm{H}$ NMR $\left(300 \mathrm{MHz}, \mathrm{CDCl}_{3}, \delta, \mathrm{ppm}\right): 5.87$ (s, $\left.1 \mathrm{H}, \mathrm{Ar}-\mathrm{CH}\right)$, $6.64(\mathrm{~s}, 2 \mathrm{H}, \mathrm{Ar}-\mathrm{H}), 6.98-7.38(\mathrm{~m}, 13 \mathrm{H}, \mathrm{Ar}-\mathrm{H}), 7.91(\mathrm{br}, \mathrm{s}, 2 \mathrm{H}$, $\mathrm{NH}) .{ }^{13} \mathrm{C}$ NMR (75 MHz, $\left.\mathrm{CDCl}_{3}, \delta, \mathrm{ppm}\right): 40.18,110.93,119.25$, $119.68,119.93,121.89,123.46,126.08,127.07,128.13,128.70$, 136.67, 143.97. MS (ESI-MS/MS, $m / z): 321(\mathrm{M}-\mathrm{H})$.

2,2'-((4-Chlorophenyl)methylene)bis(indole) [2a]: Yield: 90\%. M.p.: 76-78 C. FT-IR (KBr): 3411, 3055, 2923, 2848, $1617,1417,1337,1089,1013,743 .{ }^{1} \mathrm{H}$ NMR $\left(300 \mathrm{MHz}, \mathrm{CDCl}_{3}, \delta\right.$ ppm): 5.86 (s, 1H, Ar-CH), 6.63 (s, 2H, Ar-H), 6.97 (t, 2H, Ar-H), 7.02 (t, 2H, Ar-H), $7.14-7.36$ (m, 8H, Ar-H), 7.91 (br, s, 2H, NH) ${ }^{13} \mathrm{C}$ NMR (75 MHz, $\mathrm{CDCl}_{3}, \delta$, ppm): 39.62, 111, 119.22, 119.44, 119.83, 122.12, 123.40, 126.87, 128.33, 130.03, 131.89, 136.66, 142.45. MS (ESI-MS/MS, $m / z): 356(\mathrm{M}-\mathrm{H})$.

2,2'-((4-Methoxyphenyl)methylene)bis(indole) [2b]: Yield: 86 \%. M.p.: $186-190{ }^{\circ} \mathrm{C}$. FT-IR (KBr, $\left.v, \mathrm{~cm}^{-1}\right): 3412,2945,1602$, $1442,1242,1099,750 .{ }^{1} \mathrm{H}$ NMR $\left(300 \mathrm{MHz}, \mathrm{CDCl}_{3}, \delta, \mathrm{ppm}\right): 3.79$ (s, $\left.2 \mathrm{H}, \mathrm{OCH}_{3}\right), 5.83(\mathrm{~s}, 1 \mathrm{H}, \mathrm{Ar}-\mathrm{CH}), 6.62(\mathrm{~s}, 2 \mathrm{H}, \mathrm{Ar}-\mathrm{H}), 6.78(\mathrm{t}, 2 \mathrm{H}$, Ar-H), $6.82(\mathrm{t}, 2 \mathrm{H}, \mathrm{Ar}-\mathrm{H}), 6.96-7.31(\mathrm{~m}, 8 \mathrm{H}, \mathrm{Ar}-\mathrm{H}), 7.91$ (br, s, $2 \mathrm{H}, \mathrm{NH}) .{ }^{13} \mathrm{C}$ NMR $\left(75 \mathrm{MHz}, \mathrm{CDCl}_{3}, \delta, \mathrm{ppm}\right): 39.35,54.93$, 110.84, 113.53, 119.26, 120.03, 120.12, 121.91, 121.32, 127.09, 129.55, 136.08, 136.70, 157.91. MS (ESI-MS/MS, $m / z$ ): 351 (MH).

2,2'-((3,4-Dimethoxyphenyl)methylene)bis(indole) [2c]: Yield: $92 \%$. M.p.: $156-160{ }^{\circ} \mathrm{C}$. FT-IR (KBr, $\left.v, \mathrm{~cm}^{-1}\right): 3404,2949$, $1597,1452,1342,1138,1024,748 .{ }^{1} \mathrm{H}$ NMR $\left(300 \mathrm{MHz}, \mathrm{CDCl}_{3}, \delta\right.$, ppm): $3.76\left(\mathrm{~s}, 3 \mathrm{H}, \mathrm{OCH}_{3}\right), 3.85\left(\mathrm{~s}, 3 \mathrm{H}, \mathrm{OCH}_{3}\right), 5.82(\mathrm{~s}, 1 \mathrm{H}, \mathrm{Ar}-\mathrm{CH})$, $6.63(\mathrm{~s}, 2 \mathrm{H}, \mathrm{Ar}-\mathrm{H}), 6.73-7.36(\mathrm{~m}, 11 \mathrm{H}, \mathrm{Ar}-\mathrm{H}), 8.01(\mathrm{br}, \mathrm{s}, 2 \mathrm{H}$ $\mathrm{NH}) .{ }^{13} \mathrm{C}$ NMR $\left(75 \mathrm{MHz}, \mathrm{CDCl}_{3}, \delta, \mathrm{ppm}\right): 55.73,110.99,111.13$, $112.48,119.17,119.80,119.90,120.66,121.82,123.41,127.08$, 136.71, 136.84, 148, 149. MS (ESI-MS/MS, $m / z): 381(\mathrm{M}-\mathrm{H})$.

2,2'-(3-Phenylprop-2-ene-1,1-diyl)bis(1H-indole) [2d]: Yield: 91\%. M.p.: 96-100 oC. FT-IR (KBr, v, cm-1): 3412, 3284, 3053, 2960, 1606, 1454, 1419, 804. ${ }^{13} \mathrm{C}$ NMR (75 MHz, $\mathrm{CDCl}_{3}, \delta$, ppm): $110.90,111.20,119.09,119.67,119.89,120.26,120.50,121.01$ 121.46, 121.65, 121.75, 121.86, 126.03, 128.27, 136.51, 136.75, 147.90. MS (ESI-MS/MS, $m / z): 347(\mathrm{M}-\mathrm{H})$.

2,2'-((4-Bromophenyl)methylene)bis(indole) [2e]: Yield: 90\%. M.p.: 116-120 ${ }^{\circ} \mathrm{C}$. FT-IR (KBr, v, cm-1): 3410, 2970, 1604 1443, 802, 748. ${ }^{1} \mathrm{H}$ NMR $\left(300 \mathrm{MHz}, \mathrm{CDCl}_{3}, \delta, \mathrm{ppm}\right): 5.80$ (s, $1 \mathrm{H}$, Ar-CH), $6.82(\mathrm{t}, 2 \mathrm{H}, \mathrm{Ar}-\mathrm{H}), 7.02(\mathrm{t}, 2 \mathrm{H}, \mathrm{Ar}-\mathrm{H}), 6.99-7.86(\mathrm{~m}, 10 \mathrm{H}$ Ar-H), 8.26 (br, s, $2 \mathrm{H}, \mathrm{NH}) .{ }^{13} \mathrm{C}$ NMR $\left(75 \mathrm{MHz}, \mathrm{CDCl}_{3}, \delta, \mathrm{ppm}\right)$ : $111.93,117.92,118.70,119.18,119.44,121.40,124.04,126.89$, $130.97,131.34,137.02,144.88$. 
Table 1. Synthesis of 3,3'-bis-indolylphenylmethane using varying concentration of [Bpy][Br].

\begin{tabular}{|c|c|c|c|c|c|c|}
\hline \multirow{2}{*}{ Entry } & \multirow{2}{*}{ Reactants * } & \multirow{2}{*}{ Catalyst (mmol) } & \multirow{2}{*}{ Time (min) } & \multirow{2}{*}{ Yield (\%) } & \multicolumn{2}{|c|}{ Melting point $\left({ }^{\circ} \mathrm{C}\right)$} \\
\hline & & & & & Observed & Literature \\
\hline $\begin{array}{l}1 \mathrm{a} \\
1 \mathrm{~b} \\
1 \mathrm{c} \\
1 \mathrm{~d}\end{array}$ & $\stackrel{\text { I }}{\mathrm{H}}$ & $\begin{array}{l}0.50 \\
0.75 \\
1.00 \\
1.50\end{array}$ & $\begin{array}{l}15 \\
15 \\
15 \\
15\end{array}$ & $\begin{array}{l}82 \\
87 \\
92 \\
92\end{array}$ & $122-126$ & $124-125$ [12] \\
\hline
\end{tabular}

Table 2. Synthesis of 3,3'-bis-indolylphenylmethanes using [Bpy][Br].

\begin{tabular}{|c|c|c|c|c|c|c|}
\hline \multirow{2}{*}{ Entry } & \multirow{2}{*}{ Reactants * } & \multirow{2}{*}{ Catalyst (mmol) } & \multirow{2}{*}{ Time (min) } & \multirow{2}{*}{ Yield (\%) } & \multicolumn{2}{|c|}{ Melting point $\left({ }^{\circ} \mathrm{C}\right)$} \\
\hline & & & & & Observed & Literature \\
\hline $2 a$ & & 1.0 & 15 & 90 & $76-78$ & $76-77[38]$ \\
\hline $2 b$ & & 1.0 & 15 & 86 & $186-190$ & $190-192$ [12] \\
\hline $2 c$ & & 1.0 & 15 & 92 & $156-160$ & $155-157$ [39] \\
\hline $2 d$ & & 1.0 & 15 & 91 & $96-100$ & $98-99$ [38] \\
\hline $2 \mathrm{e}$ & & 1.0 & 15 & 90 & $118-122$ & $110-112$ [12] \\
\hline
\end{tabular}

\section{Results and discussion}

In continuation of our previous work on molten salt reaction medium [48] here, we ascertain the results obtained from the study of the synthesis of BIM using molten salt [Bpy] $[\mathrm{Br}]$ an inexpensive, eco-friendly and easily available solvent and an efficient catalyst. Scheme 1 shows the general reaction between indole and aldehyde which afford BIM as a product. The other derivatives were synthesized following the same methodology, and products synthesized are tabulated in Tables 1 and 2.

Our method not only affords the products in excellent yields but also avoids the problems associated with catalyst cost, handling, safety and pollution. We feel that the $[\mathrm{Bpy}][\mathrm{Br}]$ can act as eco-friendly catalyst, non-volatile, recyclable, nonexplosive, easy to handle, an effective medium for a variety of organic transformations. In addition to this, comparatively shorter reaction times and improved selectivity were obtained in the presence of the molten salt.

Hereafter, this section is divided in two parts, a) Tuning of molten salt, and b) Molten salt [Bpy][Br] mediated synthesis of BIMs.

\subsection{Tuning of molten salt [Bpy][Br]}

Annegret Stark [50] quoted the reality, which concerns with the effective utilization, and the significance of the solvent system in organic conversions. Solvents play an important role in governing chemical reactions. Not only are they involved in heat and mass transport, but, if chosen sensibly, they can affect an increase of the rate of reaction and selectivity, and a shift of the position of the equilibrium towards the products. In this respect the dielectric constant, polarizability, viscosity etc. properties are known to be useful in organic synthesis and for the understanding of reaction mechanisms. As found here, ionic liquids (having moderate dielectric constant) can only reach their full potential as new and alternative solvents if their physico-chemical properties and ways of interactions with solutes are fully understood.

The efficacy of the molten salt is strongly influenced by the amount of water present in it. Then, before the implementation of the strategy adopted for the synthesis of BIMs, the water content in the molten salt was determined by performing KarlFischer Titrimetry, and the water found in [Bpy] [Br] was $0.28 \%$ by mass. The TGA analysis is depicted in Figure 1, which indicates that the salt as a liquid is stable up to $200^{\circ} \mathrm{C}$.

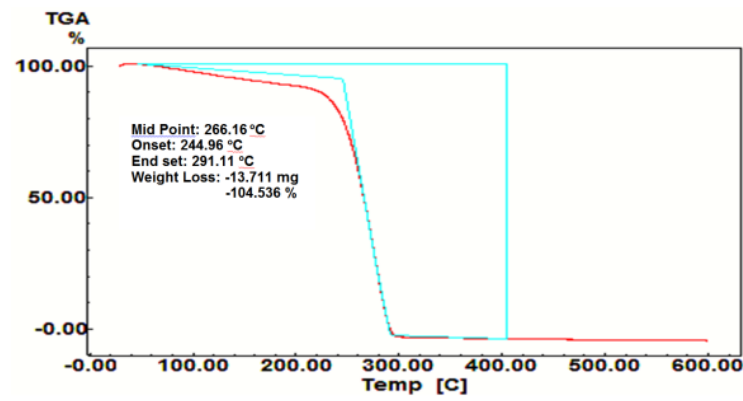

Figure 1. Thermal gravimetric details of the molten salt ( $N$-butyl-pyridinium bromide).

The UV-Visible studies of the molten salt is quite interesting, the spectrum obtained for $[\mathrm{Bpy}][\mathrm{Br}]$, shows that there is no absorption in visible region, while in UV region there is an appreciable absorption (at 243 and $233 \mathrm{~nm}$ ) due to the presence of $\pi$-electrons in pyridinium ring. It is to be noted that if an impurity is there, coloration to fused salt occurs.

\subsection{Molten salt [Bpy][Br] mediated synthesis of BIMs}

To accomplish the best results for this reaction (Scheme 1), we have studied the synthesis of 2,2'-(phenylmethylene) bis(indole) (Table 1), as a model substrate with various amount of catalyst $0.50,0.75,1.00$ and $1.50 \mathrm{mmol}$. 


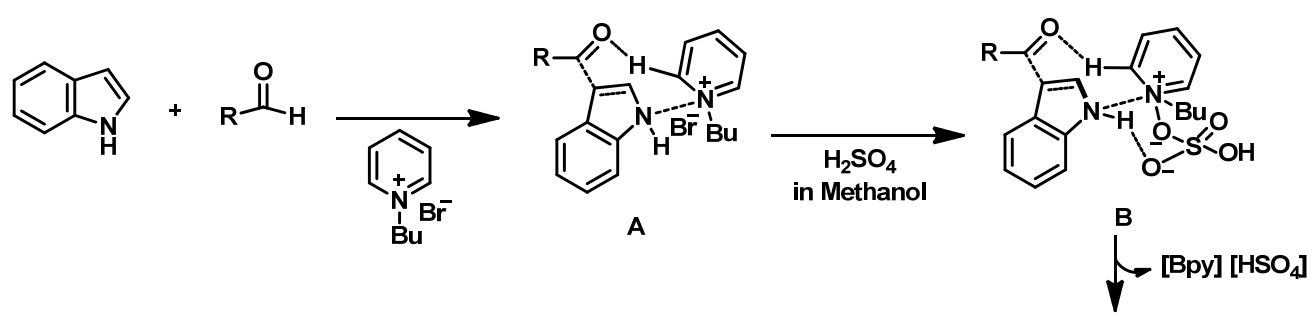

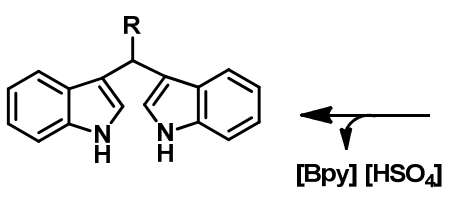

E

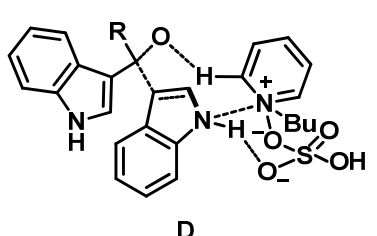

D

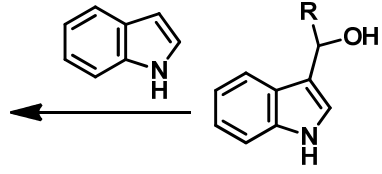

C

Scheme 2

For each reaction condition, conversion of indole $(2 \mathrm{mmol})$ and benzaldehyde (1 mmol) to 2,2'-(phenylmethylene)bis(indole) are given in Table 1 . The most satisfactory results were obtained with a 1:2:1 ratios of benzaldehyde, indole and [Bpy] $[\mathrm{Br}]$ with 15 minutes time duration.

During the course of the study, no significant difference was found in case of $\mathbf{1 a}$ and $\mathbf{1 b}$ where the concentration of the catalyst was $0.50 \mathrm{mmol}$ and $0.75 \mathrm{mmol}$, respectively, while, in case $1 \mathbf{c}$ and $1 \mathbf{d}$ where the concentration of the molten salt was $1.0 \mathrm{mmol}$ and $1.5 \mathrm{mmol}$ respectively, some improvement in the yield was obtained (Table 1).

The procedure was successfully applied for the aldehydes having substituents, which exerts $+\mathrm{R}$ effect predominantly, and their corresponding BIMs were obtained at high yields (Table 2). For most aldehydes (entries 2a-e), the yields were excellent (86-92\%). Furthermore, the reaction of indole with cinammaldehyde (entry 2d) as an $\alpha, \beta$-unsaturated aldehyde in the presence of $[\mathrm{Bpy}][\mathrm{Br}]$ has given excellent yield. All products are known compounds and were characterized by comparison of their physical and spectroscopic data with those of reported ones.

The mechanism of the catalytic action of ionic liquid [bmim] $\left[\mathrm{MeSO}_{4}\right]$ mediated synthesis of bis(indolyl)methanes was first documented by Chakraborty et al. [37]. By referring this, role of $[\mathrm{Bpy}][\mathrm{Br}]$ in catalyzing the condensation reaction between indole and aldehydes has been envisaged through the mechanistic proposal depicted in Scheme 2. As we mentioned earlier in the experimental section that the suitability of solvent system plays a crucial role in this condensation reaction, we propose for the first step of the mechanism the molten salt [Bpy] $[\mathrm{Br}]$ forming a complex in which Bpy cation undergoes electrostatic interaction with the nitrogen lone pair of the indole ring A. This complex $\mathbf{A}$ was difficult to be handling, and hence numbers of solvent and solvent systems were applied in order to achieve the desired product. Finally an effective utilization of acidified methanol system yielded the desired product. Addition of acidified methanol may be responsible for anion metathesis in situ. Subsequently the quaternary nitrogen atom of the Bpy cation undergoes electrostatic interaction with the nitrogen lone pair of the indole and enforces the $\mathrm{N}-\mathrm{H}$ hydrogen of the indole to form hydrogen bond with the oxygen atom of the $\mathrm{HSO}_{4}{ }^{-}$anion through a six-membered chair-like cyclic structure B immediately after anion metathesis. In a similar fashion, the intermediately formed indolyl alcohol (indole-3-carbinol) C undergoes a complex formation with another molecule of indole and [Bpy] $\left[\mathrm{HSO}_{4}\right]$ forming $\mathbf{D}$ which leads to the product $\mathbf{E}$ and liberates the salt back.
Our findings (Tables 1 and 2) reflect the usefulness of the method, when compared with previously reported data $[12,38$ 39] on reaction conditions and the yield of product for preparation of 3,3'-di-indolylphenylmethane. One can observe that our results show a very good comparability with previously reported data with respect to yields and reaction times. Also this method gives new direction to the use of pyridinium salt as a reaction medium for organic conversions.

\section{Conclusion}

A new method for the synthesis of bis(indolyl)methane compounds using molten salt as a reaction medium as well as a catalyst is described. The yields of the product obtained are good and the methodology applied is quite greener. A probable mechanism for the condensation reaction is suggested.

\section{Acknowledgements}

The authors are thankful to Dr. Vasudeo Parshuram Dhande for valuable guidance, as well as Mr. Anil Govind Rao Principal of Moolji Jaitha College, Jalgaon and Dr. Dilip Govind Hundiwale, Director Board of College and University Development. North Maharashtra University Jalgaon for encouragement and facilities.

\section{References}

[1]. Potewar, T. M.; Kathiravan, M. K.; Chothe, A. S.; Srinivasan, K. V. Eur. J. Chem. 2011, 2(2), 235-237.

[2]. Welton, T. Chem. Rev. 1999, 99, 2071-2083.

[3]. Fan, Y.; Zhang, S. Eur. J. Chem. 2011, 2(2), 282-288.

[4]. Angell, C.; Ansari, Y.; Zhao, Z. Faraday Discuss. 2012, 154, 9-27.

[5]. Wikes, J. Green Chem. 2002, 4, 73-80.

[6]. Vivar, O.; Lin, C.; Firestone, G.; Bjeldanes, L. Biochem. Pharmacol. 2009, 78, 469-476.

[7]. Hong, C.; Firestone, G.; Bjeldanes, L. Biochem. Pharmacol. 2002, 63, 1085-1097.

[8]. Riby, J.; Chang, G.; Firestone, G.; Bjeldanes, L. Biochem. Pharmacol. 2000, 60, 167-177.

[9]. Su, Y.; Vanderlaag, K.; Ireland, C.; Ortiz, J.; Grage, H.; Safe, S.; Frankel, A. Breast Cancer Res. 2007, 9(4), 1-14.

[10]. Sujatha, K.; Perumal, P.; Muralidharan, D.; Rajendran, M. Indian J. Chem. B 2009, 48, 267-272.

[11]. De-Kruif, C.; Marsman, J.; Venekamp, J.; Falke, H.; Noordhoek, J.; Blaauboer, B.; Wortelboer, H. Chem-Biol. Interact. 1991, 80, 303-315.

[12]. Vaghei, R.; Veisi, H.; Keyoour, H.; Firouzabadi, A. Mol. Divers. 2010, 14, 87-96.

[13]. Murugan, R.; Karthikeyan, M.; Perumal, P.; Reddy, B. Tetrahedron 2005, 61, 12275-12281.

[14]. Heravi, M.; Bakhtiari, K.; Fatehi, A.; Bamoharram, F. Catal. Commun. 2008, 9, 289-292. 
[15]. Kolvari, E.; Zolfigol, M.; Banary, H. Chin. Chem. Lett. 2011, 22, 13051308.

[16]. Sheikhshoaie, I.; Khabazzadeh, H.; Nia, S. Transit. Metal Chem. 2009, 34, 463-466.

[17]. Azizian, J.; Teimouri, F.; Mohammadizadeh, M. Catal. Commun. 2007, 8, 1117-1121.

[18]. Sharma, G.; Reddy, J.; Lakshmi, P.; Krishna, P. Tetrahedron Lett. 2004, 45, 7729-7732.

[19]. Yang, J.; Wang, Z.; Pan, F.; Li, Y.; Bao, W. Org. Biomol. Chem. 2010, 8, 2975-2978.

[20]. Reddy, B.; Sreekanth, P.; Lakshmanan, P. J. Mol. Catal. A-Chem. 2005, 237, 93-100.

[21]. Firouzabadi, H.; Iranpoor, N.; Jafarpour, M.; Ghaderi, A. J. Mol. Catal. AChem. 2006, 253, 249-251.

[22]. Khabazzadeh, H.; Sheikhshoaie, I.; Nia, S. Trans. Metal Chem. 2010, 35, 125-127.

[23]. Ma, S.; Yu, S.; Peng, Z. Org. Biomol. Chem. 2005, 3, 1933-1936.

[24]. Wang, S.; Ji, S. Synthetic Commun. 2008, 38, 1291-1298.

[25]. Sarvari, M. Synthetic Commun. 2008, 38, 832-840.

[26]. Magesh, C.; Nagarajan, R.; Karthik, M.; Perumal, P. Appl. Catal. A-Gen. 2004, 266, 1-10.

[27]. Karthik, M.; Magesh, C.; Perumal, P.; Palanichamy, M.; Arabindoo, B.; Murugesan, V. Appl. Catal. A-Gen. 2005, 286, 137-141.

[28]. Karthik, M.; Tripathi, A.; Gupta, N.; Palanichamy, M.; Murugesan, V. Catal. Commun. 2004, 5, 371-375.

[29]. Bai, G.; Ma, Z.; Shi, L.; Li, T.; Han, J.; Chen, G.; Li, N.; Liu, P. Res. Chem. Intermed. 2012, 38(9), 2501-2510.

[30]. Bandagar, B.; Shaikh, K. Tetrahedron Lett. 2003, 44, 1959-1961.

[31]. Ji, S.; Wang, S.; Zhang, Y.; Loh, T. Tetrahedron 2004, 60, 2051-2055.

[32]. Naskar, S.; Paira, P.; Paira, R.; Mondal, S.; Maity, A.; Hazra, A.; Sahu, K.; Saha, P.; Banerjee, S.; Luger, P.; Webe, M.; Mondal, N. Tetrahedron 2010, 66, 5196-5203.

[33]. Chakrabarty, M.; Ghosh, N.; Basak, R.; Harigaya, Y. Tetrahedron Lett. 2002, 43, 4075-4078.

[34]. Chakrabarty, M.; Sarkar, S. Tetrahedron Lett. 2002, 43, 1351-1353.

[35]. Praveen, C.; DheenKumar, P.; Muralidharan, D.; Perumal, P. Bioorg. Med. Chem. Lett. 2010, 20, 7292-7296.

[36]. Mulla, S.; Sudalai, A.; Pathan, M.; Siddique, S.; Inamdar, S.; Chavan, S.; Reddy, S. RSC. Adv. 2012, 2, 3525-3529.

[37]. Chakraborti, A.; Raha-Roy, S.; Kumar, D.; Chopra, P. Green Chem. 2008, 10, 1111-1118.

[38]. Deb, M.; Bhuyan, P. Tetrahedron. Lett. 2006, 47, 1441-1443.

[39]. Azizi, N.; Manocheri, Z. Res. Chem. Intermed. 2012, 38(7), 1495-1500.

[40]. Cham, H. C.; Koch, V. R.; Miller, L. L.; Osteryang, R. A. J. Am. Chem. Soc. 1975, 97, 3264-3265.

[41]. Crosthwaite, J.; Muldoon, M.; Dixon, J.; Anderson, J.; Brennecke, J. J. Chem. Thermodyn. 2005, 37, 559-568.

[42]. Bandres, L.; Giner, B.; Gascon, I.; Castro, M.; Lafuente, C. J. Phys. Chem. B. 2008, 112, 12461-12467.

[43]. Gardas, R.; Coutinho, J. Fluid Phase Equilibr. 2008, 266, 195-201.

[44]. Katritzky, A.; Lomaka, A.; Petrukhin, R.; Jain, R.; Karelson, M.; Visser, A.; Rogers, R. J. Chem. Inf. Comp. Sci. 2002, 42, 71-74.

[45]. Letaief, S.; Detellier, C. J. Mater. Chem. 2005, 15, 4734-4740.

[46]. Wang, Z.; Zhang, L.; Cukier, R.; Bu, Y. Phys. Chem. Chem. Phys. 2010, 12, 1854-1861.

[47]. Harjani, J.; Singer, R.; Garcia, M.; Scammells, P. Green Chem. 2009, 11, 83-90.

[48]. Gupta, G.; Chaudhari, G.; Tomar, P.; Waghulde, G.; Patil K. Asian. J. Chem. 2012, 24(10), 4675-4678.

[49]. Dymon, J.; Wibby, R.; Kleingardner, J.; Tanski, J. M.; Guzei, I. A.; Holbrey, J. D.; Larsen, A. S. Dalton T. 2008, 2999-3006.

[50]. Stark, A. Top. Curr. Chem. 2009, 290, 41-81. 